\title{
Bajar a servir en la ciudad de Jujuy. Servicios ciudadanos y resistencia indígena en la temprana República (1840- 1860)
}

Fecha de recepción: 28/12/2018

Fecha de aceptación: 27/05/2019

\begin{abstract}
Resumen
En la conformación del orden liberal del siglo XIX, el territorio de la Puna en la provincia de Jujuy presenta como faz ineludible de análisis la articulación de los grupos indígenas en el proceso de construcción de los estados republicanos. La composición de ese orden generó conflictos, negociaciones, adaptaciones en muchos frentes, y provocó la reconfiguración de las relaciones sociales de estos ámbitos rurales, entre ellos las nuevas obligaciones militares impuestas a la flamante ciudadanía. Considerando este campo temático, analizamos la instauración y funcionamiento de la normativa establecida respecto de los servicios militares para la población de la Puna. Retomamos el estudio de la llamada y tratada "contribución indigenal" (1840) y determinamos la reedición de este impuesto con un gravamen menos conocido por la historiografía: la exención personal (1863). Nos proponemos establecer las circunstancias históricas que pesaron en la sanción de ambas reglamentaciones, comparar ambas experiencias y proyectar sus consecuencias. Trabajamos con distintos repositorios del Archivo Histórico de Jujuy y del Archivo de la Legislatura de la Provincia de Jujuy.
\end{abstract}

Palabras clave

Sociedades indígenas Orden liberal Servicios militares Jujuy

Siglo XIX 
Keywords

Indigenous societies Liberal Order Military Service Jujuy XIX century

\section{Mots clés}

Sociétés indigènes Ordre libera Services militaires Jujuy XIX siècle

\section{Going to Serve in the City of Jujuy. Citizen obligations and Indige- nous Resistance in the Early Republic (1840-1860)}

\begin{abstract}
In the formation of the nineteenth century liberal order, the highland territory (the puna) of the Province of Jujuy presents important information for an analysis of the interaction of indigenous groups with the construction of the Republican states. The composition of that order sparked conflicts, negotiations, and adaptations on many fronts, including reconfigurations of social relations in these rural areas, and among them, the new military obligations imposed on the citizenry. Considering this thematic field, we analyzed the establishment and the functioning of regulations regarding the military service for the population of Puna. We also return to study the "indigenous contribution" (1840), re-examining the tax with a consideration of aspects less-studied in the historiography: the personal exemption (1863). We aim to establish the historical circumstances that influenced the approval of both regulations, to compare both experiences, and to understand their consequences. This work draws from different repositories in the Historic Archive of Jujuy and the Archive of the Legislature of Jujuy province.
\end{abstract}

\section{Descendre pour servir dans la ville de Jujuy. Services aux citoyens et résistance indienne dans la première République (1840-1860)}

\section{Résumé}

Pendant la conformation de l'ordre liberal au XIXè siècle, le territoire de la Puna, dans la province de Jujuy, présente une analyse très importante des peuples indigènes dans le processus de construction des États républicains. La composition de cet ordre a provoqué des conflits, des négociations et des adaptations sur de nombreux fronts. Cela favorise les relations sociales de ces zones rurales. Parmi ces relations sociales, les obligations militaires sont imposées à la nouvelle citoyenneté. Ce domaine thématique analyse l'établissement et le fonctionnement de la norme établie par rapport aux services militaires pour la population de La Puna. Nous revenons à l'étude de la "contribution indigène et nous déterminons la réédition de cet impôt avec une taxe moins connue par l'historiographie: l'exemption personnelle (1863). Nous nous proposons détablir les circonstances historiques incluses dans la sanction des deux règlements cités, de comparer les expériences et de montrer leurs conséquences. Nous avons travaillé avec les documents de l'Archive Historique de Jujuy et les archives du bâtiment du Pouvoir Législatif de la province de Jujuy.

\section{Introducción}

Platt propuso en su célebre obra Estado Boliviano y ayllu andino [...], de la década de 1980, trazar como "hilo maestro" de discusión historiográfica a futuro las relaciones -y sus vicisitudes- entre los ayllus y el Estado criollo en el siglo XIX (1980: 12). Hoy podemos decir que esta línea ha sido un campo de estudio verdaderamente fecundo que recorre numerosos aspectos y enfoques de las vinculaciones entre las poblaciones indígenas y los estados republicanos decimonónicos.

Entre los múltiples ambientes histórico-sociales y geográficos que contiene la provincia de Jujuy, la Puna es un espacio capital para poner en foco el estudio de la articulación 
de los grupos indígenas en el proceso de construcción de los estados nacionales del siglo XIX. Efectivamente, la región condensaba el escenario característico de las sociedades andinas con una numerosa y perdurable población indígena, salpicada con la presencia de mestizos y blancos en las pueblos cabeceras, que desde el orden colonial al sistema republicano mudaron su condición de súbditos de la "República de Indios" a la de "Ciudadanos" de una Nación, resignando con ello los derechos establecidos sobre los sistemas de gobierno y autoridades propias y el acceso a recursos como la tierra a través de la propiedad comunal. La condición de ciudadanía implicó un nuevo orden de derechos y de deberes. Entre estos últimos se fundaron tres servicios esenciales en virtud de la causa pública: contribuyente, trabajador productivo y soldado nacional armado. Fue a través de los tributos y del recurso de las armas que los sectores indígenas pudieron materializar la ciudadanía (Irurozqui Victoriano, 2012).

La expresión más sonada y conocida de estos procesos in situ fue la extendida oleada de rebelión indígena en todas las tierras altas de Jujuy durante la década de $1870,{ }^{1}$ en la que se denunciaron derechos de propiedad indebidos y crónicos atropellos en la cobranza y sistemas de arrendamientos. La movilización se cerró, en una primera etapa, con la expropiación de una parte importante del patrimonio de un poderoso local -el marqués de Yavi-y su conversión en tierra fiscal. Pero, se sabe, el "problema indígena" andino no estuvo supeditado solo a la "cuestión de la tierra", la construcción de los estados liberales generó conflictos, litigios, negociaciones y adaptaciones en muchos otros frentes por todo lo cual se reconfiguraron las relaciones sociales de estos ámbitos rurales. La cuestión fiscal fue esencial. En Jujuy los nuevos impuestos que se fueron creando (extracción de sal, contribución territorial, contribución mobiliaria aplicada sobre ganado y/o cosechas, sumadas a los gravámenes aduaneros establecidos en las nacientes fronteras de la Argentina, Bolivia y Chile) afectaron directa o indirectamente las bases de la economía campesina de los Andes jujeños. Hay estudios que dan cuenta de dos sucesos protagonizados por esos sectores con uso de violencia en ese contexto: la toma de la aduana ${ }^{2}$ y la receptoría del impuesto a la sal. ${ }^{3}$

Por su parte, las nuevas obligaciones militares impuestas a la flamante ciudadanía también fueron un frente de reconstitución de las relaciones del Estado con las poblaciones indígenas de la región. Como dice Gil Montero (2002: 255), durante la primera mitad del siglo XIX, el principal problema para estos actores de la Puna, más que el control y el acceso a sus tierras, fue la presencia de la guerra y la tensión consiguiente de la incorporación a las tropas. Diferentes estudios sobre estos procesos y coyunturas de guerras para el espacio de los Andes Centromeridionales han abordado en profundidad la problemática. Al examinar los episodios bélicos de enfrentamientos internos de 1870 y 1899 en Bolivia, Irurozqui demuestra que "lo militar fue crucial en la visibilización pública de los indígenas", porque

brindó a dicha población oportunidades de existencia social y política a través de la figura del "ciudadano armado" (...). La alianza entre los indios y los estamentos armados revolucionarios y gubernamentales ha evidenciado que los primeros no solo no vivieron de espaldas al proceso de construcción nacional ni fueron ajenos a las concepciones, proyectos o empresas políticas decimonónicas, sino que se constituyeron en sujetos sustanciales en la institucionalización/rearticulación territorial del Estado gracias a asumir como propia la narrativa ciudadana de cooperación nacional en su defensa grupal (2006: 44-45).

Para los estudios sobre Perú, en el mismo plano de análisis de las guerras civiles, Méndez enfatiza el carácter militarizado del Estado peruano en el siglo XIX y la importancia del involucramiento de los campesinos, por ejemplo de la región de Huanta, en las guerrillas de la década de 1830. Esa participación reportó la práctica de una ciudadanía elemental que permitió a la población indígena negociar derechos y obligaciones 
con el Estado (2005). Y afirma una premisa de carácter metodológico que ha dado suficiente aire analítico al campo de los estudios sobre la construcción de los estados nacionales decimonónicos:

La guerra (...) merece ser estudiada como algo más que un conflicto militar. Más aún cuando, dado el carácter no profesional del ejército, esta suponía, o podía suponer, la incorporación masiva de ciudadanos rurales en la toma de decisiones sobre el rumbo político del país (Méndez, 2005: 149).

Claro que la guerra y la estructuración militar de los estados republicanos constituyeron una problemática que involucró a todos los sectores sociales — no solo a los indígenas-. La historiografía latinoamericana ha removido suficientemente el sustento de los enfoques militaristas centrado en las figuras de los "grandes héroes", en la búsqueda de nuevas interpretaciones sobre los procesos revolucionarios y bélicos de la primera mitad del siglo XIX, a partir de analizar la participación de los sectores populares. En ese campo de estudio la intervención de estos grupos en las fuerzas militares permite hoy comprender, en un sentido amplio y como canal de expresión, que ello implicó un rico aprendizaje y una experiencia que confirió una cultura política propia (Fradkin, 2008; Morán, 2011). La observación de las milicias como reflejo de la política incluye, en un plano más concreto, el análisis de la construcción de la ciudadanía y la manifestación de diversas formas de acciones públicas colectivas que remiten a la "ciudadanía en armas" (Macías, 2010; Irurozqui Victoriano, 2015).

Ligados a los aspectos políticos, el reclutamiento y las prestaciones militares de los grupos subalternos provocaron profundos efectos sociales, especialmente en los espacios rurales. ${ }^{4}$ El servicio de las armas configuró un espacio social de tensión, de disciplinamiento y de negociación; basado no solo en apremios (como las levas forzosas y los castigos) sino también en el otorgamiento de premios y en la generación de estímulos materiales y simbólicos. Así, los fueros, derechos sobre tierras, exenciones impositivas a cambio del servicio, dispensas de las obligaciones privadas como el pago de los arriendos, ganancias salariales y pensiones (Paz, 2008; Mata de López, 2009; Davio, 2010) significaron todo un orden de recompensas necesariamente convenidas con las tropas para procurar la adhesión y la fidelidad.

Conectado a este marco temático y campo historiográfico en este artículo se analizan la instauración y funcionamiento de la normativa y la práctica establecida respecto de los servicios militares para la población de la Puna. Para ello retomamos el estudio de la llamada y tratada "contribución indigenal" (1840) y determinamos la reedición de este impuesto con un gravamen menos conocido por la historiografía: la exención personal (1863). Nos proponemos establecer las circunstancias históricas que pesaron en la sanción de ambas reglamentaciones, examinarlas comparativamente y proyectar su incidencia en las relaciones de poder y conflictividades sociales desatadas en consecuencia. Trabajamos con distintos repositorios del Archivo Histórico de Jujuy y del Archivo de la Legislatura de la Provincia de Jujuy.

\section{Instituciones especiales para un territorio “díscolo”. Ejércitos y gue- rras en la Puna}

En la Puna a mediados del siglo XIX, se concentraba todavía la mayor parte de la población (con un $30 \%$ del total de Jujuy) y estaban establecidas algunas de las más ricas y enormes haciendas de la provincia; en los departamentos de la Puna se hallaba la principal riqueza inmobiliaria rural provincial, sin contar las propiedades urbanas cercanas a la ciudad capital. Estas haciendas se orientaban principalmente a la 
percepción de cuantiosas rentas generadas en los pagos y servicios personales que la masa indígena campesina hacía en concepto de arriendos, por el uso de la tierra para morada y por la explotación de pastoreo de ganado menor y en pequeña escala que realizaba como principal medio de sustento.

La Puna era también una de las regiones geográficamente más alejadas del centro administrativo y gubernamental capitalino en la incipiente demarcación fronteriza con Bolivia y Chile. Sus pobladores sostenían un comportamiento "díscolo", acrecentado por esa distancia geográfica que a menudo dificultaba la tarea de control social de los agentes estatales. Esa situación existía desde los tiempos coloniales cuando el Cabildo de Jujuy debió lidiar arduamente con diferentes intereses en su intento de afirmar su jurisdiccionalidad. ${ }^{5}$

En la república liberal la gobernabilidad de la Puna debió asegurarse con la presencia y el mando efectivo de funcionarios y organismos excepcionales en el concierto de la institucionalidad gestada para toda la provincia. ${ }^{6}$ También fue peculiar la creación de juzgados propios de primera instancia en la Puna como una forma especial de intervención estatal en la zona (Fandos, 2018). Igualmente, se dotó a la región de regímenes especiales para la regulación de los deberes de "defensa de la patria". Efectivamente, la contribución directa de la Puna fue un gravamen impositivo que rigió entre $1841 \mathrm{y}$ 1851, por el que se eximieron las obligaciones militares de la población de esta región, al modo de una capitación, con alcance restringido a esa territorialidad.

Para la jurisdicción de Jujuy y la impronta de las guerras de la primera mitad del siglo XIX, Paz determina que la movilización miliciana desde 1812 y hasta la caída del sistema de Güemes ${ }^{7}$ impactó en las relaciones sociales agrarias y étnicas, con la consiguiente erosión de ciertas jerarquías coloniales por la privación de mano de obra a la que se vieron sometidos los patrones y la suspensión en el pago de los arrendamientos y el amparo de los fueros militares (Paz, 2008). El autor enfatiza la constitución de un grupo social producto de ese proceso: los "gauchos", quienes tuvieron significativa presencia en todo el territorio de Jujuy salvo, quizás, con la excepción de la Puna. Incluso en la quebrada de Humahuaca la figura del gaucho comenzó a ser reconocida tras la conformación de tempranos contingentes reclutados por los maestros de postas y al mando de los principales hacendados, convertidos en sus jefes militares.

En cuanto a la Puna, las indagaciones de Gil Montero expresan las particularidades del proceso en esta región. La incorporación de esta población a la Guerra de Independencia era un asunto complejo por la presunción y percepción de la oficialidad militar de la falta de lealtad y entrega a la causa patriótica que aquellos profesaban. Esta autora comprende que la militarización en la primera mitad del siglo XIX fue menos profunda debido a que la bases de las milicias que actuaban se conformaban y se dirigían fuera de la región, y nucleaban a los "hombres de abajo", de los valles y la quebrada de Humahuaca. Por su parte, la eximición del pago de los arriendos, a los que estaba sujeto el grueso de esta población a cambio del servicio militar, también fue un medio de atracción para comprar su fidelidad. Aunque los puneños no escaparon a la incautación y saqueo de su ganado, la implementación de la contribución directa los habilitó para evitar la obligación del servicio en las milicias, entre 1840 y 1852 (Gil Montero, 2004). Creemos que se trata de una medida diferenciada de otros usos dispensadores del servicio de armas establecidos en el espacio del ex Virreinato del Río de La Plata. En ese ámbito fue común, por ejemplo, dejar fuera del alcance del enrolamiento a capataces de campos, hijos únicos de madres viudas y enfermos (Macías, 2010: 78). La principal diferencia radica en que estas situaciones se planteaban para casos puntuales e individuales, mientras la contribución directa de la Puna tuvo el carácter de recurso fiscal — de carácter voluntario si se quiere - pero que recaía de modo impersonal sobre todos los vecinos de la Puna. Similar lectura podemos hacer 
de otro instrumento corriente en el siglo XIX conocido como el sistema de "personero", por el cual el titular afectado al servicio militar pagaba a un reemplazante efectivo un monto, por lo general, elevado y desparejo (Davio, 2010: 94; Macías, 2010: 80; Literas, 2014-2015). Si bien en todas las formas citadas la meta era evitar el enrolamiento, las particularidades tanto de la contribución directa de la Puna como del derecho de exención personal que operó en la provincia en la década de 1860 - que veremos luego-, radicó en que fueron parte en su momento del régimen impositivo de Jujuy, con tasas prefijadas por ley y homogéneas.

\section{Entre la Contribución Directa de la Puna (1841-1851) y la Contribu- ción Indigenal (1853)}

La Contribución Directa de la Puna ha sido tratada en la historiografía regional desde tres ópticas. Delgado presenta la temática desde el análisis de las estructuras fiscales en los orígenes de la conformación de Jujuy como provincia (década de 1830). Considera que la instauración de este particular impuesto obedeció a las necesidades del fisco, al reforzamiento de la soberanía territorial de la zona por parte del gobierno provincial y "a la inserción de las comunidades indígenas en las estructuras políticas, administrativas y legales de la provincia” (Delgado, 1993). Destaca su aportación a las endebles arcas públicas con una participación en los ingresos del 20 al 25\% entre 1841 y 1851.

Gil Montero encuadra su examen a partir de la relación entre Estado e indígenas, propia de la etapa republicana, trayendo al ruedo la problemática de la pervivencia de los tributos indígenas en las sociedades andinas. ${ }^{8}$ Repasa la concepción de "pacto colonial de reciprocidad" como una renegociación del tributo colonial en Bolivia a cambio de sostener la posesión sobre las tierras comunales, citando para el caso los estudios de Platt. Igualmente destaca el carácter asimétrico, más que de un pacto, entre los caudillos locales y las poblaciones indígenas que adoptó el tributo en Ayacucho, por el cual se producía un drenaje de recursos de los segundos a los primeros, según Bonilla. Con la referencia a este autor se introduce otro caso analizado donde imperó un creciente empobrecimiento y militarización del aparato estatal. En definitiva, en el recorrido bibliográfico que hace Gil Montero enfatiza la flexibilidad de significados que adoptó el tributo indígena en los Andes Centromeridionales durante el siglo XIX (2002: 244-246). Secundando esta idea y para sumar otro sentido del tributo republicano, por nuestra cuenta, recuperamos también los estudios de Méndez. Esta autora relaciona el tributo con la milicia para el caso peruano con la alusión a la práctica del intercambio de acción militar directa de los campesinos indígenas en las guerras de independencia y las guerras civiles por la exoneración del tributo. Esta negociación del asunto partía de la idea de que la asistencia en las milicias "era una manera alternativa de prestar servicios al Estado, o sea, de cumplir con un deber ciudadano (...)" (Méndez, 2005: 142). Agrega que el universo social donde operó este mecanismo - Huanta - presenta una sustancial diferencia con los ayllus del norte potosino examinados por Platt, ya que en su universo de análisis la mayoría de las comunidades indígenas había perdido sus derechos sobre las tierras comunales, era tributaria sin tierras, por lo cual no tenía sentido entonces un "pacto tributario" (2005: 113). Ese patrón se asemeja más al caso jujeño, pero el acuerdo establecido fue en dirección inversa.

Efectivamente, Gil Montero introduce la experiencia de la contribución directa de la Puna en 1840, como un tributo pactado a cambio de la eximición del enrolamiento en la milicia - en vez del mantenimiento de sus tierras-, a consecuencia de la dura experiencia que resultó en esta región el desarrollo de las Guerras de Independencia y de la Confederación Peruano-Boliviana (Gil Montero, 2002). Además, subraya esa particularidad en el hecho de que en la Puna jujeña había una discordancia entre tributo 
y tierras porque las poblaciones indígenas se habían diferenciado claramente durante la colonia según sus posibilidades de acceso a la tierra. Así, por un lado, existía un grupo de indios encomendados de Casabindo y Cochinoca, integrados al complejo económico del Marquesado de Tojo, que gozaban de pleno derecho a la propiedad comunal, por su condición de originarios. Por otro lado, las poblaciones indígenas no encomendadas eran "forasteros sin tierras", asentados en haciendas privadas mediante el sistema de arrendamiento. Según la autora, a fines del siglo XVIII "dos de cada tres indígenas de la Puna carecían de derechos sobre las tierras" y eran arrendatarios (Gil Montero, 2006: 392). El perfil se profundizó y se generalizó en los tiempos republicanos. Entonces "los indígenas, antes originarios y forasteros con sus enormes diferencias internas, eran vistos como una masa homogénea de campesinos arrendatarios sin muchas distinciones" (Gil Montero, 2006: 394). Estos sujetos de la Puna tuvieron una relación precaria con la tierra: los que ya pagaban arriendos desde la colonia lo siguieron haciendo a partir de la Independencia. Los indígenas con propiedad comunal transmutaron en arrenderos, perdieron indefectiblemente sus derechos a la tierra.

Finalmente, Bushnell, interesado en indagar los fenómenos que fueron extraños al régimen rosista, por ser de poca importancia desde la perspectiva porteña, se aboca al estudio de la política indígena en Jujuy, precisamente en los tiempos de Juan Manuel de Rosas. Emprende así el estudio de lo que denomina "experimentos" locales: la desarticulación de la propiedad comunal en la quebrada de Humahuaca por la vía enfitéutica y la Contribución Directa de la Puna de 1840. Sin entablar mayores interlocuciones con los estudios de referencia sobre los tributos indígenas de la zona andina en la etapa republicana, califica la segunda temática como un "tributo colonial revivido", fundado en el descontento indígena de la Puna por el servicio militar. Con su análisis acentúa el hecho como producto de la resistencia indígena a cumplimentar esa carga derivada de la "igualdad ciudadana", por un lado, y como una política del gobierno jujeño para acentuar en esa región "soberanía por la vía fiscal", en vez de hacerlo por el reclutamiento militar (Bushnell, 1997: 74-77).

Nuestro estudio pretende añadir algunas aportaciones a estas interpretaciones. Para ello, optamos por puntualizar con mayores detalles los contextos específicos de creación de estos mecanismos de exenciones militares.

La Ley de Contribución Directa de la Puna de la década de 1840 establecía que los vecinos de los cuatro departamentos de la región (Rinconada, Santa Catalina, Yavi y Cochinoca) podrían adscribirse voluntariamente a la exención del enrolamiento en las milicias, mediante el pago efectivo de un canon anual de tres pesos per cápita, destinado al sostén del Estado. De lo contrario, la no suscripción al impuesto implicaba la obligación de enrolamiento e incorporación a los cuerpos reglados de las milicias provinciales, sujetos "a prestar servicios personales debidos al Estado". Aunque no lo explicita, involucraba a la población masculina, sin una determinación de la mayoría de edad más que la alusión al hecho de ser "legalmente emancipado" y tener hasta sesenta años.

Pese a que la ley figura como sancionada en la compilación de leyes en febrero de 1840 , el registro documental que nos marca el pulso cotidiano de los sucesos hasta llegar a su creación (sobre todo en la correspondencia oficial sostenida por el gobierno central y los jefes políticos de cada distrito existentes en el Archivo Histórico de Jujuy) determina que en realidad la preparación de esta ley se produjo recién a partir de mediados de ese año. ${ }^{9}$

Acompañó como contexto político la llegada al poder de los hombres que comprometieron la participación de Jujuy en la Coalición del Norte. Esta fuerza, de tinte unitario se conformó tras el pronunciamiento de la provincia de Tucumán contra Juan Manuel 
de Rosas, al desconocer su carácter de gobernador de Buenos Aires y al oponerse a la delegación en su persona de las relaciones exteriores. Ello implicó la adscripción de Jujuy a la causa unitaria y el consecuente aporte de hombres y recursos a las fuerzas militares alineadas en este bando. De este modo, la Contribución Directa de la Puna se materializó en medio de esta coyuntura, que coincidió con el gobierno provincial de Roque Alvarado (abril de 1840-septiembre de 1841). Esta circunstancia de guerra civil interna no ha sido señalada por los estudios existentes sobre el referido tributo, que lo asociaron particularmente a la Guerra de la Confederación Peruano-Boliviana (1837-1839).

Ese flamante gobierno provincial unitario promovió una obra pública en la ciudad capital de gran magnitud: la reparación del templo de La Merced. El emprendimiento alcanzó a toda la población a raíz de las demandas de trabajo y/o contribuciones monetarias. Para el caso de la Puna, se solicitó a partir de junio de 1840 la remisión de diez hombres por departamento, a fin de relevar a los que ya se hallaban trabajando en la reparación del templo. ${ }^{10}$ En general no hubo presentación voluntaria en esta región y solo se logró enviar un contingente procedente de Yavi que, sin embargo, emprendió la fuga en la marcha hacia la ciudad. ${ }^{11}$ En cambio, los habitantes de la Puna sí cumplimentaron remesas, al modo de costas, de limosnas voluntarias para el proyecto edilicio de la ciudad.

Pero las demandas de prestaciones públicas a los ciudadanos de la Puna se extendieron hacia otros servicios republicanos casi en simultáneo con los requerimientos de las obras de La Merced. Efectivamente, en septiembre de ese año los jefes políticos de los cuatro departamentos de la Puna fueron notificados del envío de veinticinco hombres por departamento para el servicio de la Guarnición del Principal en la Ciudad de Jujuy, por un período estimado de dos meses, para turnarse con los milicianos citadinos y de sus alrededores sobre quienes recaía siempre esa obligación. La Guarnición del Principal fue una dependencia del antiguo edificio del cabildo donde se guarecía una tropa permanente de milicianos para brindar seguridad a la ciudad, era la sede de la principal cárcel de la provincia y, con el tiempo, llegó a albergar a la banda de música provincial. Por la reconstrucción lograda sabemos que desde 1826 existía una Compañía de Cívicos de Artesanos que brindaba gratuitamente este servicio a falta de una fuerza a sueldo para estos fines. Entre sus tareas centrales se mencionan el patrullaje durante la celebración de las ferias comerciales que reunían numerosa gente procedente de la campaña, la vigilancia de la cárcel, prestaciones de trabajo en obras públicas y la seguridad del orden público citadino. ${ }^{12}$ Hasta mediados de la década de 1830 no hay indicios de funcionamiento estable de la guardia porque quizás se seguían sosteniendo estas prestaciones públicas a partir de la constitución del cuerpo de los artesanos. Desde $1833-\mathrm{y}$ mayormente desde 1834 - comienza a visualizarse una serie de gastos que incluyen indistinta y discontinuamente hasta comienzos de la década de 1840 "socorros" monetarios para guardias y escoltas, provisión semanal de velas, a veces leña y raciones alimenticias. Incluso en los presupuestos de gastos inventariados desde esta época aparece un ítem que especifica gastos en guerra, guardia, escolta y expediciones. De manera que ubicamos la puesta en funcionamiento de esta guarnición de la ciudad en la década de 1830. El reclutamiento de los efectivos de la guardia se hacía sobre la población masculina de toda la provincia como una exigencia ciudadana y pública.

Recibida la orden de presentación en la Guardia en la Puna, inmediatamente, los encargados de concretar el oficio dieron cuenta de la dificultad para efectivizar la tarea encomendada. Primero porque la mayor parte de los hombres aptos para esa prestación estaba ausente recorriendo las tierras bajas y en los valles en la búsqueda de su subsistencia en sus habituales viajes de "abastecimiento". Segundo, por negativa expresa de los actores quienes 
han resuelto no habenirse [sic] salir de este abandonando a su familia y cortar alimentos de que subsisten y si están prontos a contribuir con lo que justamente puedan según sus fuerzas, que de soldados de ningún modo [cursiva propia], y por algún acontecimiento le quieren obligar primero serán víctimas del rigor o escaparan a la inmediata República [en alusión a Bolivia], no hay razón que les dentre [sic], no hay consejo que les convensa [sic].13

En tercer lugar, como otra muestra de oposición, se reportó que la mayoría de los pobladores huyó para esconderse "desde que reunieron los 10 hombres que mandaba a trabajos de esa capital y fugaron todos a los dos jornadas que caminaban (...) me parece imposible reunir ese número (..." ${ }^{14}$ En otra correspondencia se sostenía que "los habitantes de este departamento se hallan muy alucinados y escabrosos por el mal tratamiento que recibieron años atrás, en tiempos del general Aleman". ${ }^{15}$ Finalmente, la resistencia alcanzó incluso la forma de amotinamiento y fuga. Así sucedió con el único contingente que se logró despachar desde Cochinoca, acción en la que pregonaron "que no quieren ir a la capital", porque no eran soldados. ${ }^{16}$

El fuerte movimiento de oposición que gestó la convocatoria no se agotó en la sola negativa, también se materializó en sucesivas reuniones populares donde se pergeñaron los términos de una negociación, que "gustosamente" proclamaron, que era la de contribuir con un aporte de dinero para el socorro de las tropas. ${ }^{17}$ Así, en poco tiempo, las poblaciones de la Puna convinieron la trasmutación de las obligaciones exigidas por el Estado en trabajo público y en servicios militares. En síntesis, de septiembre a octubre de 1840 fructificó la ley llamada de Contribución Directa de la Puna. El bando oficial de resolución que se publicó en cada paraje público puneño decía:

Por cuanto los jefes políticos de los departamentos de la puna han informado la repugnancia y oposición que forman los individuos de los cuatro curatos de la puna para bajar a esta capital ha donde han sido llamados en número de 25 hombres cada departamento a hacer la fatiga en el principal turnando con los milicianos de esta que siempre la hacen (...) ha resuelto el gobierno considerar también la distancia y perjuicios (...) de esta fecha no serán citados, ni molestados los indígenas de los cuatro curatos de la Puna, para presentar servicio militar alguno en esta capital ni en las provincias de abajo por ninguna que sea la exigencia. ${ }^{18}$

Lo explicitado en la fundamentación de esta contribución nos hace pensar que la experiencia reflejó, parafraseando a Falcón (2015), la "dialéctica del poder". En su análisis de los jefes políticos de México, la autora adscribe el término para explicitar una concepción del dominio que resulta siempre relativo, incluso para quienes son los más poderosos, por la improbabilidad de que puedan controlar todos los resortes de la sociedad. Por el contrario, en este modo de entender el poder es factible que diferentes agentes - aun las comunidades indígenas - puedan inscribirse en una dialéctica de apoyo y, a la vez, de rechazo a participar en la negociación del poder. Más aún, la contribución directa de la Puna se trató de un tributo transado y concertado, en los mismos términos del "pacto colonial negociado" que Soux reconoce para la jurisdicción de Charcas, no en el contenido del pacto en sí mismo sino en el sentido de fundarse a través de "formas de negociación por parte del Estado y los grupos indígenas, opciones que se abrían conforme se reconocía al otro como sujeto político" (Soux, 2008: 45).

Como ha sostenido Contreras (2005) al evaluar este tipo de "tributos" en la república decimonónica peruana, también en la Puna jujeña el universo de sujetos concernidos en el impuesto tuvo un determinado perfil social y una marca étnica. Aunque deliberadamente se proclamó su aplicación a todos los varones adultos residentes en los cuatro departamentos de la Puna, los discursos producidos sobre el tema demuestran la asociación del tributo a la categoría indígena. Así, en la fase de creación de la ley, se 
reparó en la eliminación de la palabra "naturales" como sujetos imponibles, dejando solo la de "avecindados", por la acotación que la primera hacía solo a una clase de habitantes y para asegurar su competencia a toda clase de sociedad según el derecho vigente de igualdad civil (Bushnell, 1997: 76). En cambio, esa claridad que buscaba saldarse en el texto escrito de la norma no se tradujo literalmente al momento de implementarla; de la incertidumbre sobre quiénes recaía se hicieron eco las autoridades de Yavi que consultaron "si la enunciada contribución se entendía exclusivamente a la clase indígena o si era comprensiva a todos los habitantes de ese departamento. ${ }^{19}$

Nos preguntamos si el hecho de que la Contribución Directa de la Puna fuera casi una solución emanada desde las bases y no impuesta desde las esferas de poder favoreció su implementación y aseguró su leal cumplimiento. Creemos que no absolutamente. La puesta en ejercicio, en realidad, desató un sinfín de dificultades y conflictos a pesar de su relativo éxito en términos de recaudación fiscal para las arcas del gobierno, como bien ha subrayado Delgado (1993).

Cuadro 1. Puna de Jujuy. Distribución departamental del Padrón de la Contribución Directa (1841).

\begin{tabular}{|c|c|c|c|}
\hline Curato & Estimado & Pagado & Adeudado \\
\hline Rinconada & 1.380 & 865,3 & 514,5 \\
\hline Yavi & 1.892 & 995,3 & 896,4 \\
\hline Cochinoca & 1.751 & $1.575,6$ & 175,2 \\
\hline Santa Catalina & 800 & 800 & 0 \\
\hline Totales & 5.823 & 4.236 & $1.586,2$ \\
\hline
\end{tabular}

Fuente: elaboración propia en base a AHJ. Caja Documento, año 1842, Jujuy, 7 de marzo de 1842.

Como queda reflejado en los datos del cuadro precedente, en general, el nivel de acatamiento del impuesto fue relativamente alto, el déficit no superaba el $27 \%$ de lo estimado como ingreso. Los departamentos de Santa Catalina y Cochinoca fueron los que llegaron a completar la obligación en mayor medida. Por su parte, la situación de Yavi expresa mayor endeudamiento, ya que aunque era la zona de mayor aporte en relación a los otros departamentos, solo logró reunir el 52\% de lo calculado como ingreso en 1841.

Cuando el pago no se hacía efectivo, una de las razones esgrimidas fue la insolvencia de los sujetos empadronados. En este sentido, es destacable el registro de la situación de pobreza generalizada que dibujan los jefes políticos en sus informes. Esa condición se asociaba a la indigencia a veces provocada por factores ambientales, ${ }^{20}$ pero también al sistema de dominación — se habla de "opresión" - procedente tanto de las esferas privadas como públicas. Una y otra vez sale a la luz en estos relatos la simultaneidad de este impuesto con onerosas erogaciones que recaían sobre las espaldas de los campesinos puneños, entre ellas el peso creciente de los arriendos adeudados a los patrones hacendados, así como los derechos de aduana que pagaban por "los alimentos que buscan en otras provincias". ${ }^{21}$ Desde Cochinoca también se expresó que no se podía realizar a término la recaudación porque "están exigidos a un mismo derecho por sus arrendamientos".22 Así, los indígenas de la Puna pagaban por el uso de la tierra y pagaban por la sustracción de la milicia. 
También se repite como patrón de conducta la ausencia de los contribuyentes (por los habituales viajes de intercambio y provisión de bienes de subsistencia) lo que dificultaba las cobranzas y obligaba a continuas prórrogas de las fechas de liquidaciones establecidas (San Juan y Navidad). ${ }^{23}$ Por esta realidad, en ocasiones, los propios agentes estatales locales salieron al resguardo de los contribuyentes mediante la anticipación del valor de las cuotas departamentales con capitales personales. ${ }^{24}$ En líneas generales, al analizar pormenorizadamente la contribución directa de la Puna funcionando in situ queda una imagen de aceptación y condescendencia. No obstante, también existieron grupos abiertamente reaccionarios al pago que se expresaban alegando

(...) que han prestado servicios en las guerras de independencia y que hoy de tributarios no pueden estar y hecho presentes a algunos al Sr. comisionado general quien me dijo formase una lista de todos los que han ido después del empadronamiento para dar contribución a Bolivia. (AHJ. Caja Documento, año 1841, Yavi, 25 de junio de 1841)

Si bien debemos someter a un análisis pormenorizado cómo se resolvió militarmente cada situación de beligerancia durante esta etapa, nos consta que, por lo general, las fuerzas de custodia, vigilancia y movilizadas eran establecidas en la quebrada de Humahuaca desde donde operaban hacia la Puna. Por ejemplo, en la incursión de los unitarios emigrados a Bolivia hacia mediados de 1846 se conformó una "División de Vanguardia y Expedicionaria en Humahuaca". ${ }^{25}$

Resulta elocuente la querencia que adquirió el tributo como un verdadero amparo frente a los posibles requerimientos del Estado provincial. En los momentos más álgidos del enfrentamiento entre unitarios y federales, durante la vigencia de la Coalición del Norte y durante toda la década de 1840, cualquier exigencia de reunión de milicianos en la Puna era rechazada mediante el resguardo legal de la Contribución Directa. Como ejemplo sirva la respuesta del jefe político de Yavi al oficio de remisión de los hombres excluidos de contribución y destinados al servicio militar para completar un contingente de la Puna de cien hombres: "debo decir que en este departamento no ha quedado un solo hombre destinado a prestar sus servicios personales, porque todos son contribuyentes". ${ }^{26}$ Cuando llegó a Cochinoca el jefe político reproducía la respuesta de los habitantes, con un tono más desafiante, en los siguientes términos:

se encuentra que no tiene absolutamente un solo individuo de que echar mano, respecto de ser pagadores sin excepción de persona y que actualmente se está haciendo efectiva la recaudación de la contribución, y a mas con la orden del gobierno que a ningún contribuyente se los ocupe en servicio alguno (...) se disculpan y desobedecen al juez, a esto se agrega que no tiene el juez una lanza ni cosa que se le parezca a harma [sic] para hacer obedecer. ${ }^{27}$

La Contribución Directa de la Puna fue abolida en 1851, aunque fue brevemente restablecida con el nombre de Contribución Indigenal en 1853. Los fundamentos de la derogación son tratados originalmente en el estudio de Bushnell. ¿Por qué se derogó? Según el autor, no fueron razones de índole fiscal en el sentido de su bajo rendimiento sino más bien variables políticas (Bushnell, 1997: 78-79). En efecto, esta ley de revocación fue parte de un corpus legislativo emanado de un gobierno que emprendió una serie de reformas legales, condensadas en la nombrada "Undécima Legislatura". Se trata del grupo unitario actuante en la Liga Unitaria de la década de 1830 y en la Coalición del Norte contraria a Rosas, nucleado a inicios de 1850 por su férrea oposición a Mariano Iturbe (quien había ejercido la gobernación de la provincia entre 1841 y 1849), figura que encarnaba el rostro más duro del sistema de la Federación rosista. Habían logrado representación política a partir del gobierno conciliador de Castañeda (1849-1851) y su sucesor José López Villar (Medina, 2016: 348-351). En esa 
circunstancia, junto a la supresión de la Contribución Directa de la Puna, se abolieron fueros militares y eclesiásticos — señala Bushnell-. A lo que podemos agregar la Ley de Elección de Jueces, la Ley de Elecciones de Representantes de la Sala Provincial, la Ley de Debates de la Sala ${ }^{28}$ y una Ley de Administración de Justicia en la que se incorporó dentro de la arquitectura judicial un órgano especial y de mayor apelación para la región, el Juzgado de Primera Instancia de la Puna (Fandos, 2018). Con la bandera del liberalismo político, el grupo mentor de estas leyes adoptó los principios liberales como una táctica de oposición al régimen local rosista, catalogado como despótico, arbitrario y tiránico (Medina, 2016: 343-348).

A tono con esos principios esgrimieron la injusta sujeción de una de las regiones más pobres de la provincia, agravada por un ciclo adverso de plagas y sequías, al gravamen de la Contribución Directa. Pero, además, argumentaron que no había razón para seguir sosteniéndola puesto que el Estado provincial jujeño había logrado acentuar soberanía en ese territorio, no existían mayores apremios fiscales y la disminución del peligro de guerras había reducido los acrecentados requerimientos de reclutamiento militar. Por su lado, la continuidad del tributo de la Puna fue defendida por "razones de Estado", dada la fuerte dependencia del erario público de ese ingreso; pero también se buscó contrarrestar el supuesto de la miseria de los habitantes de la región mediante la comparación con los enormes desembolsos que sus compatriotas de los valles bajos y de la Quebrada realizaban por el servicio de las armas.

En su balance, Bushnell entiende que la Contribución Directa "aunque 'un pecho' considerable les liberó a los indígenas puneños de una obligación militar también incómoda" (Bushnell, 1997: 84). En todo caso, estos fueron los argumentos tejidos en el marco de una disputa política facciosa y por el control del poder; nos resta poder acceder también a las voces propias afectadas con el gravamen de quienes sabemos que inicialmente en forma voluntaria negociaron y adscribieron a este recurso.

\section{El Derecho de Exención Personal (1863-1871). ¿Una reposición del tributo indígena de la década de 1840 ?}

El cambio de época que inauguró la segunda mitad del siglo, a la par del impulso que tomó la conformación del Estado nacional, vino acompañado de una reestructuración de las fuerzas militares. Su organización cobró ímpetu con la reforma introducida por el presidente Urquiza para dotar un ejército de jurisdicción nacional, el que quedó conformado por el Ejército de Línea (exclusivo de profesionales, oficiales de carrera y soldados pagos), los "enganchados", de manera libre o coercitiva, y la guardia nacional formada por todos los ciudadanos. La creación de esta última "imprimió un carácter nacional a una institución -la milicia- que hasta entonces había sido netamente local, y si bien las milicias provinciales no desaparecieron, pasaron a ocupar un rol cada vez menor en el entramado militar" (Macías y Sábato, 2013: 73).

En esta etapa se atribuye a la institución de la guardia nacional un rol clave para la construcción de la ciudadanía. Hoy en día existe una variedad de perspectivas en los estudios que la tienen como objeto central de investigación. Una de ellas, asociada a la concepción de "ciudadanía armada", la concibe como un instrumento vital del Estado nacional para incentivar en los individuos las conductas y deberes cívicos, en especial el patriotismo y la lealtad nacional, o dicho de otra manera, analiza cómo esta institución militar fomentó la formación de ciudadanos y delineó las características de los mismos. Desde otro acercamiento, se mira a la guardia nacional como principal mecanismo de disciplinamiento de la población rural y de las sociedades de fronteras, en especial en la interrelación con las poblaciones indígenas. Finalmente, hay una línea orientada 
al estudio de determinados actores como los comandantes y sus articulaciones en las relaciones de poder. ${ }^{29}$

Esa nueva realidad - y su impacto- apenas es advertida en la historiografía sociopolítica de Jujuy. Según Paz, desde mediados del siglo XIX, con la presencia de las agencias estatales nacionales (aduanas y guardias nacionales), se englobó a las poblaciones hasta entonces ligadas a la lógica política de las elites provinciales y, a su vez, con la consolidación del Estado en la década de 1870 se "puso punto final a las resistencias populares" del tipo que protagonizaron los indígenas de la Puna en el levantamiento de mediados de esa década (Paz, 2010: 175).

Pero en el decenio de 1860 vino la prueba de fuego para la flamante guardia nacional y las tropas del ejército de línea de Jujuy por las demandas militares que crearon la Guerra del Paraguay y la presencia de Felipe Varela en el territorio del norte argentino (Fandos, 2019b). La organización del plantel militar en la provincia según la nueva normativa nacional que obligaba a todos los ciudadanos argentinos entre los 17 y los 60 años a formar parte de la guardia nacional, llegó con dos meses de demora y se ejecutó con la orden de la presentación masiva de los afectados para el 11 de junio de 1854. Desde entonces la evidencia documental devela que fue un proceso donde fluyeron diversas controversias de poder y con fuertes reticencias en su formación. En el territorio provincial la organización más tardía, frenada por la propia resistencia, fue la de los destacamentos de los departamentos de la Puna. ${ }^{30}$ La población de la Puna prácticamente no concurría a las convocatorias de empadronamientos de la guardia nacional y, además, los batallones no lograban completarse por la práctica establecida en esta población de ausentarse "en sus diligencias particulares, y otros directamente fugitivos pasándose para Bolivia o Salta”. ${ }^{31}$

Especialmente en la Puna, las diversas expresiones constatadas muestran que se trató de una de las milicias menos colaborativas y más reacias a las causas que oficialmente se reconocían en nombre de la "defensa de la patria". Pero, al fin, en la década de 1860, la formación de batallones de las guardias nacionales departamentales al mando de hombres fuertes del poder local (dueños de haciendas y principales comerciantes), así como el despliegue de toda la logística de esta institución en territorio propio, implicó una nueva vivencia miliciana en estas poblaciones campesinas. Verdaderamente el servicio de las armas se impuso entonces en el nuevo contexto en esta región.

Precisamente en este momento y en esta circunstancia se legalizó, una vez más, un mecanismo de evasión de la obligación miliciana. Efectivamente, entre 1863 y 1871 tuvo vigencia una ley que dispensaba del servicio rotativo y transitorio (por quince días al año) para la guarnición del piquete principal de la ciudad capital - al que estaban obligados los ciudadanos de toda la provincia-, mediante el pago voluntario de un impuesto de 4 reales anuales:

Todo ciudadano de la provincia alistado o no en la guardia nacional, para ser exencionado del servicio que debe prestar en el principal de esta ciudad con el objeto de mantener el orden público, pagará 4 reales anuales. Exceptuados los que tengan impedimentos físicos o morales, no tengan la edad o aptitudes requeridas por las leyes vigentes para el servicio militar. ${ }^{32}$

Como vemos la dispensa sigue siendo para el servicio a la guardia capitalina que ahora comprendía toda la población adulta y masculina de la provincia - no solo de la Puna-, sin afectar en esta eximición la obligatoriedad del alistamiento en el ejército y/o en la guardia nacional. Para entonces la guarnición de la ciudad había sido reestructurada, bajo el nombre de "piquete del principal" y con un incremento del número de efectivos. 
Desde la abolición de la Contribución Indigenal los indígenas de la Puna volvieron a estar sujetos a la prestación de servicio en esta guardia; con ello se restablecieron los mismos problemas de antes. A cada mandato del envío de agentes de cualquiera de los cuatro departamentos puneños siguen oficios que ponen sobre aviso la imposibilidad de la remisión por estar las casas vacías, sus dueños ausentes, de viaje de intercambio o como arrieros, ${ }^{33}$ porque el trabajo habitual de estos es el oficio del hilado y no la naturaleza de los trabajos para lo cual se los convoca, porque "tienen atenciones de primera necesidad, sin que haya brazos suficientes para que estén (...) durante la ausencia en que se ocupan en marchar más de ochenta leguas a esa capital a trabajo de quince días" ${ }^{44}$ Algunos de los funcionarios emisores de estas misivas intercedían ante las autoridades centrales pidiendo la exoneración de la exigencia. Pero otros lo interpretaban como reflejo de los hábitos de desobediencia más comunes en estos poblados. Es evidente que la cuestión seguía siendo un motivo de malestar y, por eso, las noticias de la sanción del decreto de exención personal fueron acogidas en los siguientes términos

(...) antes de ahora se les hizo comprender con bastante extensión y claridad respecto de las fuertes obligaciones que tienen de llenar cumplidamente a lo que contestaron conformes, unanimes [sic] y contentos, en general de ellos han satisfecho muy cumplidos los derechos [...] sin la mas pequeña repugnancia. ${ }^{35}$

Así, pese a que el texto de la norma de la exención personal nada indica de su relación con la anterior experiencia del tributo de la Puna, en la expresión de estos relatos y en los fundamentos de su creación y de su derogación se advierten sus conexiones.

A la hora de implementarla pesaron fundamentos de justicia porque su práctica se hacía coactivamente sobre sectores labradores de las zonas más cercanas a la ciudad sin que tuvieran participación gente de los departamentos más distantes - en clara alusión a los ciudadanos de la Puna-, obligándolos a desatender el trabajo cotidiano del que dependía el principal sustento familiar. Pero, además, había razones económicas puesto que la provincia carecía de recursos para sostener este cuerpo de seguridad y vigilancia, por lo cual una alternativa de solución era la autofinanciación por el pago de la exención personal, tal como procuraba esta ley.

Aunque se tomaba como ejemplo de esta subvención un modelo foráneo, el de los EE.UU., la medida también resonó como inconstitucional para algunos diputados porque era lisa y llanamente un "tributo", siendo "igual en todo al que antes de la constitución abonaban los indígenas de la Puna y que cesó de cobrarse desde la jura de la Constitución". ${ }^{36}$ Evidentemente, el alegato retomaba la experiencia de la Contribución Indigenal de la década de 1840.

El "tributo" de eximición a la prestación militar en el piquete citadino, refundado en la década de 1860, fue abolido en 1871 dejando sus propias huellas. En primer lugar, no llegó a adquirir mayor relevancia como fuente de ingresos, entre otras cuestiones porque estaba dirigido principalmente a los sectores menos pudientes, "a la clase de jornaleros, artesanos y otros que con el sudor del día ganan su alimento y casi nunca les sobra para el día siguiente". ${ }^{37}$ Según los datos proporcionados por los presupuestos provinciales, este recurso - a diferencia de la contribución directa de la Puna- fue de mínima importancia (Cuadro 2). 
Cuadro 2. Provincia de Jujuy. Relación del derecho de exención personal y los recursos generales (1864-1870).

\begin{tabular}{|c|c|c|c|c|c|c|c|}
\hline & 1864 & 1865 & 1866 & 1867 & 1868 & 1869 & 1870 \\
\hline $\begin{array}{c}\text { Exención } \\
\text { Personal }\end{array}$ & 1.900 & 2.000 & 1.000 & & 800 & & 700 \\
\hline Totales recursos & 34.212 & 41.728 & 42.492 & 42.735 & 53.474 & 73.712 & 74.834 \\
\hline
\end{tabular}

Fuente: elaboración propia sobre la base del Registro Oficial (1885). Compilación de Leyes y decretos de la provincia de Jujuy. Desde 1853 hasta el de 1884. Tomos II y III. San Salvador de Jujuy,

Tip. Libertad de José Petruzzelli.

Desde una máxima representatividad proyectada en alrededor del 5\% cuando se implementó el impuesto, la tendencia fue descendente y en algunos años no se cobró. Desde esta lectura queda claro que la exención personal estaba lejos de significar la fuente de recaudación que supuso el tributo de los años 40 , en todo caso solo se buscaba que la guardia se autofinanciara por este medio. La debilidad del impuesto fue producto de la poca vigilancia en su recaudación, también de la inestabilidad que provocó la guerra en esos años ${ }^{38} \mathrm{y}$, mayormente, de la desidia popular en hacerlo efectivo. Ciertamente no fue sistemático el esfuerzo gubernamental por asegurar su cobro. Además, muchos veían en este instrumento fiscal "un arma política" en varios sentidos. Como era "odiado" por los sectores populares propendía a aminorar su exigencia para evitar la mala voluntad de esas masas. A su vez, promovía la proliferación de una guardia compuesta por los ciudadanos más carenciados y bajos de recursos, favorable a comportamientos desorganizados, indisciplinados y "subversivos (...) dispuestos a aceptar las doctrinas más destructoras como una verdad política incuestionable." ${ }^{39}$

Las manifestaciones de resistencia al impuesto se alzaron principalmente por la superposición de cargas y servicios militares, y por el recelo que creaban las exceptuaciones de algunas regiones al cumplimiento del mismo. Lo que muestra la documentación es que había una negativa a pagar la exención mientras se oficiara activa y paralelamente de guardia nacional, ya fuera con la asistencia a las pruebas doctrinales de los días domingo o porque estaban simultáneamente movilizados en algún operativo; se hablaba del peso desmedido de una continua "fatiga". A lo que se sumaba el hecho constatado de que los mismos sujetos que debían pagarlo eran acreedores del Estado por los servicios de armas efectivizados y que se les adeudaban en forma crónica. Por ejemplo, la gente del departamento de Tumbaya

contestaron en voz alta que no pagaban este impuesto, a no ser que se les pague la expedición a Yavi, de la limpieza de camino de tránsito del año pasado, de los auxilios que en el servicio fueron suministrados durante la guardia en toda esta vía después que pasó Varela. Además que este derecho no lo conocían por decreto nacional..$^{40}$

Por otro lado, los pobladores de las regiones afectados al pago emitieron quejas sobre ciertos privilegios que gozaban determinadas zonas dispensadas de la obligación. En esa dirección, el Comandante de la Guardia Nacional de Humahuaca, expresó en 1866 que

(...) ajustándose al oficio recibido procedió a noticiar a oficiales y milicianos del $4 \%$ de exención personal y contestaron que no convienen en pagar dicho impuesto mientras sean guardias nacionales de la provincia y que en prueba de ello se ocupan los domingos en pruebas doctrinales (...) que sabe que por esta razón están exonerados de esta pensión el cuerpo de cívicos de la Capital, San Lorenzo y Ledesma no pagan y también el escuadron [sic] de Tilcara.41 
Hemos reunido algunos datos sobre rendiciones de pago de este derecho, de modo de aproximarnos a una distribución zonal del impuesto, que presentamos traducidos en el Cuadro 3.

Cuadro 3. Jujuy. Registro del pago del derecho de exención personal por departamentos (1865-1869) y su representatividad según la población.

\begin{tabular}{|c|c|c|c|c|c|}
\hline \multirow[b]{2}{*}{ Departamento } & \multicolumn{2}{|l|}{1865} & \multicolumn{2}{|l|}{1868} & \multirow[b]{2}{*}{$\begin{array}{c}\text { \% Censo } \\
1869 *\end{array}$} \\
\hline & $\begin{array}{c}\mathrm{N}^{\circ} \\
\text { Contribuyentes }\end{array}$ & Valores & $\begin{array}{c}\mathbf{N}^{\circ} \\
\text { Contribuyentes }\end{array}$ & Valores & \\
\hline Tumbaya & 61 & 90,5 & & & 18 \\
\hline Tilcara & 324 & 160 & & & 78 \\
\hline Yavi & 491 & 244,4 & 356 & 125 & 66 \\
\hline Rinconada & 300 & 150 & & & 57 \\
\hline San Antonio & & & 114 & 67 & 50 \\
\hline $\begin{array}{l}\text { Perico del } \\
\text { Carmen }\end{array}$ & & & 120 & 60,40 & 12 \\
\hline Totales & & 645 & & 261 & \\
\hline
\end{tabular}

Fuente: elaboración propia sobre la base de AHJ. Caja Documentos, Comprobantes hacienda de los años 1865 y 1869. Primer Censo de la República Argentina (1872), año 1869, pp. 574-575. Buenos

Aires, Imprenta El Porvenir. Los valores expresados en pesos bolivianos. *En esta columna incorporamos la relación de contribuyentes del impuesto con los varones de entre 16 y 60 años registrados en el censo.

En cuanto a los departamentos y años faltantes, creemos que en su gran mayoría esto obedece a que no se conservaron en el archivo los padrones comprobatorios de los impuestos pagados (los que incluían contribución territorial, contribución mobiliaria, canon de enfiteusis para la Quebrada, derecho agrícola y derecho de exención personal) pese a que se hacían efectivos. La excepción fue el caso de los departamentos de Ledesma y San Pedro que sí elevaron informes de las cuotas pagadas de todos los otros impuestos, menos de este. Así, pudimos constatar la veracidad de los reclamos proclamados en la Quebrada, ya que regían dispensas geográficas especiales. Las mismas alcanzaban las citadas jurisdicciones de Ledesma y San Pedro en donde los varones activos para la milicia estaban eximidos de la carga de guardia del piquete citadino cuando habían sido convocados a otros servicios como prestaciones en obras públicas en la Capital o cuando se les encomendaba la realización de estas en sus zonas de residencia. ${ }^{42}$

Además, una reglamentación anterior había establecido la exceptuación a los "puesteros" y a los peones traídos de fuera de la provincia al servicio de las "haciendas de industria agrícola", de cualquier servicio público y fatigas ordinarias. ${ }^{43}$ La medida tenía un claro significado: proteger las actividades económicas y los intereses de los hacendarios de los valles bajos de Jujuy —entre ellos el sector azucarero- y asegurar de este modo la provisión de la mano de obra. 
La organización de puestos era un modo de trabajo y de producción típico de las grandes fincas ubicadas en las tierras bajas, centrado en la figura del puestero, quien debía una prestación mínima gratuita al año (en la cosecha o yerra) para el propietario, a tiempo completo cuidaba del ganado repartido en el monte por lo cual percibía un salario y recibía la cesión gratuita de tierra para él y su familia para morada y siembra de aprovechamiento individual (Holmberg, 1988 [1904]: 73). El otro universo protegido de las fatigas públicas ordinarias eran los contingentes indígenas trasladados desde la región del Chaco como peones de las haciendas azucareras. Evidentemente había girado el orden de necesidades desde la primera mitad del siglo XIX, cuando prevaleció la eximición del servicio militar a las poblaciones de la Puna con la ventaja adicional de altos suministros de ingresos fiscales, respecto de la segunda mitad, etapa en que fue prioritario cubrir a determinados sectores del trabajo.

Resta decir que al examinar en el propio terreno la práctica del derecho de exención personal durante los años en que estuvo vigente no hemos encontrado voces opositoras a la medida, o incómodas con ella, procedentes de la región de la Puna. Ya regían otros impuestos que afectaron, directa o indirectamente, a las economías campesinas de estas poblaciones y que fueron el blanco de diversas manifestaciones de protestas, quejas y hasta de motines. ${ }^{44}$

Sin embargo, una problemática seguía siendo clave. Se había sumado en esta etapa, además del servicio en la guardia urbana (de la cual estaba previsto eximirse) y en la guardia nacional, la posibilidad del reclutamiento para el ejército de línea, que sí era altamente resistido. Un mecanismo introducido por los poderes locales fue el reclutamiento con la excusa de mover guardias de la región de la Puna, que no pagaban el impuesto de 4 reales, para "trabajos" en la guarnición principal de la ciudad cuando, en realidad, el destino consistía en completar las filas del ejército nacional durante la Guerra del Paraguay (Fandos, 2019b). A medida que la estrategia se fue conociendo entre los propios afectados, generó el lógico rechazo, dado que "ninguno quiere marchar de buena voluntad y como también que no creen que es para trabajar sino para que los manden a las filas". ${ }^{45}$ Por ejemplo, en Yavi el Comandante del Batallón 4, informó que no era posible cumplir esas misiones porque "los notificados se me han opuesto fuertemente que no pueden marchar a aquel destino porque estos no son hombres de trabajo sino de campo, hilado y telar y que también sin gravamen alguno ganan tres reales en esta y que le es un perjuicio ir sesenta leguas a trabajar". ${ }^{46}$

\section{Palabras finales}

Nuestra principal intención ha sido revisar y analizar la instauración y funcionamiento de la reglamentación sobre los servicios de milicias referidos al territorio de la Puna, en tensión con cada momento histórico, entre las décadas de 1840 y 1860. En este sentido, reseñamos los principales estudios sobre la llamada Contribución Directa de la Puna de 1840 y propusimos un análisis mayormente situado en los procesos de militarización de la región, a la vez que extendimos el tratamiento de la temática a una etapa de la que no se tenía mayor conocimiento.

Tanto en los años 40 como en los 60 , fecha esta última en que consideramos hubo una reedición modificada del anterior tributo con el nombre de Exención Personal, la prestación militar en cuestión - para la cual se crearon ambos mecanismos de transmutación del servicio en persona por un desembolso monetario- fue el de las guardias rotativas que había que hacer en resguardo de la Ciudad de Jujuy. 
En la primera experiencia, entre 1841 y 1851, el mecanismo estuvo ordenado en forma exclusiva para los ciudadanos de la Puna y la circunstancia imperante fue la guerra intestina entre federales y unitarios. Es decir que la guerra era un desafío presente en ese momento y dio fundamento, primero, a un movimiento de resistencia de la población puneña a implicarse mayormente en él y, segundo, a tejerse una estrategia de negociación favorable para ellos y para el propio Estado. Más allá de las peripecias detectadas en los cobros del tributo, es preciso destacar que a la población de la Puna le fue posible evadir con la implementación de este recurso fiscal, de una manera legal y legítima, su deber ciudadano de defensa de la patria, por diez años y en tiempos en que las presiones por las guerras no fueron menores. A partir de la guerra de la Coalición del Norte, el territorio de la Puna fue invadido cinco veces desde Bolivia por los emigrados políticos unitarios en la década de 1840 (Conti, 2006: 134).

La herramienta impositiva puesta en funcionamiento en 1863 se hizo para una misma problemática (proveer a la guarnición de la ciudad) y con la memoria viva del antecedente de los años 40, pero ahora en el marco de otro contorno sociopolítico y socioeconómico. Eran los años en que la principal materia castrense radicó en dar forma a un ejército de carácter nacional, teniendo como principal instrumento la conformación de las guardias nacionales. Y, además, fue el momento de impulso de ciertas actividades económicas que nucleaban a los principales centros productores de ganado mayor, cereales y caña de azúcar de las tierras bajas de Jujuy, los que requirieron que los principales sectores exentos de las "fatigas" públicas pasaran a ser los trabajadores implicados en ellos. Tampoco hubo mayor propósito estatal en la percepción de la "exención personal" que la de autofinanciar el propio funcionamiento del piquete del principal. Por cierto, mientras sucedían estos procesos, la década de 1860 tampoco fue una etapa pacífica dado el desarrollo de la Guerra del Paraguay y del levantamiento federal de Felipe Varela.

En ese marco, en la Puna, por un lado, se acentuó la militarización de los habitantes comunes llamados - sin excepción y por la fuerza del disciplinamiento- a completar la obligación del enrolamiento en las guardias nacionales. Por otro lado, en apariencia, la población adscribió favorablemente a la nueva obligación fiscal para eximirse de la guardia citadina, y no hubo mayores señales de conflicto en tanto y en cuanto se pudieran valer de ese recurso legal.

El problema se suscitaba para estas poblaciones, en uno y otro momento, cuando el servicio obligaba a "bajar a servir a la Ciudad". Los habitantes de la Puna desde distintas posiciones se reconocían ciudadanos contribuyentes, o campesinos, hiladores o tenderos con capacidad contributiva, pero lo que verdaderamente se rechazaba y, menos aún se pensaba como negociable, era "ser soldados" de la República. 


\section{O Bibliografía citada}

"Aramendi, B. (2017). El distrito de la Puna y su primer subdelegado. Intendencia de Salta del Tucumán, 1784-1795. En Fronteras de la Historia, 22, (1) pp. 12-37. Bogotá, Instituto Colombiano de Antropología e Historia.

"Becerra, M. F. y Estruch, D. (2011). Alcaldes de mina, capitulares, cateadores y mineros. Una reflexión sobre la administración de la justicia en las causas mineras de la Puna de Jujuy (siglo XVII). En Revista de Historia del Derecho, 42, pp. 1-21. Buenos Aires, Instituto de Investigaciones de Historia del Derecho.

» Bushnell, D. (1997). La política indígena de Jujuy en época de Rosas. En Revista de Historia del Derecho 25, pp. 59-84. Buenos Aires.

»Canciani, L. (2012). La Guardia Nacional en Argentina durante la organización nacional: balances y perspectivas historiográficas.En História Unisinos, 16 (3), pp. 391-402. São Leopoldo.

»Conti, V. (2006). De las Guerras de la Independencia a la Organización del Estado. 1810-1852. En Teruel, A. y Lagos, M. (dirs.). Jujuy en la Historia. De la colonia al siglo XX, pp. 87-137. San Salvador de Jujuy, EDIUNJu.

»Contreras, C. (2005). El impuesto de la contribución personal en el Perú del siglo XIX. En Histórica, XXIX, 2, pp. 67-106. Lima.

»Davio, M. (2010). Los sectores populares militarizados en la cultura política tucumana. 1812-1852. Tesis Doctoral en Ciencias Sociales, Universidad Nacional de General Sarmiento e Instituto de Desarrollo Económico y Social (IDES). Buenos Aires. Disponible en: https://www.ungs.edu.ar/posgrados/ sectores-populares-militarizados-en-la-cultura-politica-tucumana-1812-1854 (Consultado: 17/03/2019).

»Delgado, F. (1993). Estructura política, administrativa y económica del Estado provincial. Jujuy (1934-1852). En Campi, D. (coord.). Jujuy en la historia, avance de investigación 1, pp. 79-97. San Salvador de Jujuy, UNIHR.

»Falcón, R. (2015). El Jefe Político. Un dominio negociado en el mundo rural del Estado de México, 1856-1911. México, El Colegio de México.

»Fandos, C. (2018). Justicia y territorialidad indígena. La experiencia del juzgado de primera instancia de la Puna Jujeña. En Claves. Revista de Historia, 4, (6), pp. 43-72. Montevideo.

»----. (2019a). "Viva la Santa Federación, mueran los salvajes Unitarios". El régimen rosista, los subdelegados y el gobierno de la Puna Jujeña en la década de 1840. En Gutiérrez, M. y Citterio, D. (comps.). Historia breves de Jujuy II. Actores y prácticas de poder en los siglos XIX y XX, pp. 64-73. San Salvador de Jujuy, UNIHR/CIITeD, Cuadernos del Duende, Jujuy.

»-----.(2019b). La campaña de Jujuyentre la Guerra del Paraguayy el levantamiento de Varela: manifestaciones socieconómicas en Jujuy a mediados del siglo XIX. En Revista Quinto Sol, 23 (2), mayo-agosto, pp. 1-20. Santa Rosa.

»Fradkin, R. (2008). Cultura política y acción colectiva en Buenos Aires (18061829): Un ejercicio de exploración. En Fradkin, R. (ed.). ¿Y el pueblo dónde está? Contribuciones para una historia popular de la revolución de independencia en el Río de la Plata. Buenos Aires, Prometeo. 
" Gil Montero, R. (2002). Tierras y tributo en la Puna de Jujuy. Siglos XVIII y XIX. En Faberman, J. y Gil Montero, R. (comps.). Los pueblos de indios del Tucumán Colonial, pervivencia y desestructuración, pp. 203-255. Quilmes, EDIUNju/ Universidad Nacional de Quilmes Ediciones.

"----. (2004). Guerras, hombres y ganado en la Puna de Jujuy: Comienzos del Siglo XIX. En Boletín del Instituto de Historia Argentina y Americana QDr. Emilio Ravignani凶, 25, pp. 9-36. Buenos Aires.

»----. (2006). La Puna: población, recursos y estrategias. En Teruel, A. y Lagos, M. (dirs.). Jujuy en la Historia. De la colonia al siglo XX, pp. 375-401. Jujuy, EDIUNJu.

» Holmberg, E. (1988 [1904]). Investigación Agrícola de la provincia de Jujuy. Buenos Aires Compañía Sudamericana de Billetes de Banco.

»Irurozqui Victoriano, M. (2006). ¿Ciudadanos armados o traidores a la patria? Participación indígena en las revoluciones bolivianas de 1870 y 1899. En Iconos. Revista de Ciencias Sociales, 26, pp. 35-46. Quito.

»----. (2012). Tributo y armas en Bolivia. Comunidades Indígenas y estrategias de visibilización ciudadana, siglo XIX. En Mundo Agrario, 13 (25). La Plata.

»----. (2015). “A resistir la conquista”. Ciudadanos armados en la disputa partidaria por la revolución en Bolivia, 1839-1842. En Boletín del Instituto de Historia Argentina y Americana $₫ D$ r. Emilio Ravignani®, 42, primer semestre, pp. 60-91. Buenos Aires.

»Literas, L. (2014-2015). Aportes para el estudio de las resistencias al servicio miliciano en la campaña bonaerense: los personeros de nueve de julio (segunda mitad del siglo XIX). En Anuario IEHS, 29 y 30, pp. 97-116. Tandil.

"Macías, F. (2010). Poder ejecutivo, militarización y organización del Estado Provincial: Tucumán en los inicios de la Confederación Rosista. En Boletín del Instituto de Historia Argentina y Americana “Dr. Emilio Ravignani”, 32, enero-junio, pp. 69-105. Buenos Aires.

" Macías, F. y Parolo, M. P. (2010). Guerra de independencia y reordenamiento social. La militarización en el norte argentino (primera mitad del siglo XIX). En Iberoamericana, X (37), pp. 19-38. Pittsburgh.

» Macías, F. y Sábato, H. (2013). La Guardia Nacional: Estado, Política y uso de la fuerza en la Argentina de la segunda mitad del siglo XIX. En Polis, 6 (11), pp. 70-81.

"Madrazo, G. (1982). Hacienda y encomienda en los Andes. La Puna de Jujuy bajo el marquesado de Tojo, siglos XVII-XIX. Buenos Aires, Fondo Editorial.

»Mata de López, S. (2009). Guerra, Militarización y Poder. Ejército y Milicia en Salta y en Jujuy. 1810-1816. En Anuario IEHS, 24, pp. 279-298. Tandil.

»Mata, S. (2012). La herencia de la guerra: Salta (Argentina) 1821-1831. En Nuevo Mundo Mundos Nuevos. Disponible en: http://journals.openedition.org/ nuevomundo/63221 (Consultado: 11/05/2019).

" Medina, F. (2016). Poder político en Jujuy y relaciones interprovinciales a fines del régimen rosista. La representación de la obra de teatro Lanuza en 1851. En Americana, Revista de Estudios Latinoamericanos de la Universidad Pablo de Olavide, 4, pp. 335-371. Sevilla.

»Méndez, C. (2005). Tradiciones liberales en los Andes o la ciudadanía por las armas: campesinos y militares en la formación del estado peruano. En Irurozqui Victoriano, M. (ed.). La mirada esquiva. Reflexiones históricas sobre la interacción 
del estado y la ciudadanía en los Andes (Bolivia, Ecuador y Perú), siglo XIX, pp. 125154. Madrid, Consejo Superior de Investigaciones Científicas.

»Morán, D. (2011). La historiografía de la revolución. La participación plebeya durante las guerras de independencia en el Perú y el Río de la Plata. En Nuevo Mundo Mundos Nuevos. Disponible en: http://nuevomundo.revues.org/61404 (Consultado: 05/10/2017).

» Paz, G. (1991). Resistencia y rebelión campesina en la Puna de Jujuy, 1850-1875. En Boletín del Instituto de Historia Argentina y Americana "Dr. Emilio Ravignani", 3-4, pp. 63-89, Buenos Aires.

»----. (2008). Reordenando la campaña: la restauración del orden en Salta y Jujuy, 1822-1825. En Fradkin, R. (ed.). ¿Y el pueblo dónde está? Contribuciones para una historia popular de la revolución de independencia en el Río de la Plata, pp. 209-222. Buenos Aires, Prometeo.

》----. (2010). Resistencias populares a la expansión y consolidación del Estado nacional en el interior: La Rioja (1862-1863) y Jujuy (1874-1875). En Moreno, O. (coord.). La construcción de la nación Argentina. El rol de las fuerzas armadas, pp. 105-115. Buenos Aires, Ministerio de Defensa.

»Platt, T. (1982). Estado boliviano y ayllu andino. Tributo y tierras en el Norte de Potosí. Lima, Instituto de Estudios Peruanos.

"Sica, G. (2014). Las otras mitas. Aproximaciones al estudio de la mita de plaza en la Jurisdicción de Jujuy, gobernación de Tucumán, siglo XVII. En Anuario de Estudios Americanos, 71 (1), pp. 201-226. Sevilla.

»Sica, G. y Ulloa, M. (2010). Jujuy en la colonia. De la fundación de la Ciudad a la crisis del Orden colonial. En Teruel, A. y Lagos, M. (dirs.). Jujuy en la Historia. De la colonia al siglo XX, pp. 43-84. Jujuy, EDIUNJu.

"Soux, M. L. (2008). Tributo, constitución y renegociación del pacto colonial. El caso altoperuano durante el proceso de Independencia. En Relaciones, XXIX 115, pp. 10-48. Zamora.

\section{Fuentes}

\section{Secundarias}

»Primer Censo de la República Argentina, año 1869. (1872). Buenos Aires, Imprenta El Porvenir.

»Registro Oficial. (1885). Compilación de Leyes y decretos de la provincia de Jujuy. Desde 1853 hasta el de 1884, Tomo II. Jujuy, Tip. Libertad de José Petruzzelli.

"Registro Oficial. (1885). Compilación de Leyes y decretos de la provincia de Jujuy. Desde 1853 hasta el de 1884, Tomo III. Jujuy, Tip. Libertad de José Petruzzelli.

\section{Primarias}

"Archivo Histórico de Jujuy. Cajas Documentos, años 1840 a1870, correspondencia oficial, comprobantes de hacienda, informes fiscales.

» Archivo Histórico de la Legislatura de Jujuy. Cajas Documentos, comunicaciones oficiales. Libros de Actas de Sesiones. 


\section{Cecilia Fandos}

Doctora en Historia. Investigadora Independiente en CONICET (Unidad de Investigación en Historia Regional-CIITeD) y Profesora Asociada Ordinaria de la cátedra de Historia Económica y Social de la Universidad Nacional de Jujuy (Argentina). Investiga temas sobre la historia regional e historia agraria de los siglos XIX y XX. Coautora del libro Quebrada de Humahuaca, estudios históricos y antropológicos en torno a las formas de propiedad (2014), Jujuy, EDIUNJu. Y coordinadora del texto El Desarrollo Regional de Jujuy en la Argentina Agroexportadora. Análisis y Perspectivas desde la Historia (2018), con la misma editorial. El último título publicado en revistas científicas es "Entre la Guerra del Paraguay y el levantamiento de Varela: manifestaciones socioeconómicas en Jujuy a mediados del siglo XIX" (2019). En Revista Quinto Sol, 23 (2). 
1 La convulsión se manifestó en los departamentos de Cochinoca, Yavi, Santa Catalina y Rinconada en la quebrada de Humahuaca (Humahuaca y Tilcara).

2 Este levantamiento se hizo en función de las elevadas tasas de aduana aplicados a productos tradicionales de intercambio con el valle de Tarija, como el maíz y la coca; en contra de las penalizaciones efectuadas cuando no se formalizaba el pago de derechos aduaneros (Paz, 1991: 76).

3 El impuesto a la sal afectó un recuso explotado desde antes de la conquista y servía básicamente para el intercambio comercial que efectuaban estas poblaciones indígenas (Madrazo, 1982: 152).

4 Podríamos citar al respecto referencias de diversos universos geográficos estudiados desde esta perspectiva. Como ejem plo aludimos a Macías y Parolo (2010) y a Mata (2012).

5 Cfr. Sica y Ulloa (2010); Becerra y Estruch (2011); Sica (2014) y Aramendi (2017).

6 De hecho las figuras borbónicas de subdelegados, de origen colonial, fueron refundadas según la nueva realidad político-institucional en la década de 1840. En el ordenamiento de la provincia de Jujuy, desde su autonomía, únicamente en la Puna se conformaron las subdelegaciones para su gobierno en el siglo XIX (Fandos, 2019a).

7 El término alude a la etapa que transcurrió entre 1815 y 1822 en la jurisdicción salto-jujeña, cuando bajo el liderazgo de Martín Miguel de Güemes se desarrolló un tipo de táctica bélica contra las fuerzas realistas conocida como "guerrilla", y una forma de movilización miliciana que adscribió a los sectores populares y poblaciones campesinas de la región, reconocidos como "gauchos".

8 Recordemos que las Cortes de Cádiz y la Constitución gaditana habían suprimido el tributo indígena en el nuevo orden liberal que procuraban instaurar. En el caso de los territorios adscriptos en la jurisdicción del Virreinato del Río de la Plata, el asunto se hizo explícito en las resoluciones de la Junta Grande de 1811 y en la Asamblea del Año XIII, en la que quedaron abolidos el tributo y la mita.

9 No tenemos explicación para el hecho de haberse registrado la sanción de la ley en febrero de 1840 , pero sí absoluta certeza de que fue recién en el segundo semestre de ese año que la temática salió a la luz.

10 Archivo Histórico de Jujuy (en adelante AHJ). Caja Documento, año 1840, Rinconada, 28 de junio de 1840; Cochinoca, 22 de julio de 1840; Yavi, 14 de agosto de 1840 .

11 AHJ. Caja Documento, año 1840, Yavi, 4 de septiembre de 1840.

12 AHJ. Caja Documento, año 1826, Jujuy, 3 de mayo de 1826. 
13 AHJ. Caja Documento, año 1840, Santa Catalina, 19 de septiembre de 1840.

14 AHJ. Caja Documento, año 1840, Yavi, 8 de septiembre de 1840.

15 AHJ. Caja Documento, año 1840, Yavi, 16 de septiembre de 1840.

16 AHJ. Caja Documento, año 1840, Cochinoca, 22 de septiembre de 1840.

17 AHJ. Caja Documento, año 1840, Yavi, 16 de septiembre de 1840.

18 AHJ. Caja Documento, año 1840, Jujuy, 9 de octubre de 1840.

19 AHJ. Caja Documento, año 1840, Yavi, 14 de noviembre de 1840.

20 Particularmente en 1841 se verificó una sequía que afectó la cría de ganado, principal “ramo de subsistencia”. AHJ. Caja Documento, año 1841, Santa Catalina, 12 de abril de 1841.

21 AHJ. Caja Documento, año 1842, Rinconada, 12 de enero de 1842; Yavi, 4 de enero de 1842.

22 AHJ. Caja Documento, año 1841, Cochinoca, 30 de marzo de 1841.

23 AHJ. Caja Documento, año 1841, Yavi, 12 de abril de 1841.

24 AHJ. Caja Documento, año 1841, Santa Catalina, 12 de abril de 1841. Yavi, 18 de diciembre de 1843. Cabría pensar qué implicancias tenían los cubrimientos de estos déficits del impuesto en las relaciones originadas a partir de allí entre un sujeto pagador/acreedor y sus deudores.

25 AHJ. Caja Documento, año 1846, Jujuy, 13 de julio de 1846.

26 AHJ. Caja Documento, año 1841, Yavi, 5 de febrero de 1841.

27 AHJ. Caja Documento, año 1841, Cochinoca, 17 de marzo de 1841.

28 Las reformas introducidas aminoraban en buena medida el poder exorbitante del ejecutivo para equipararlo con el de los poderes legislativo y judicial (Medina, 2016: 351-353).

29 El recorrido historiográfico citado fue tomado de Canciani (2012: 391-402).

30 En la Puna se organizó la guardia nacional recién en 1867. Efectivamente, en mayo de ese año se crearon cuatro batallones, cuyas planas mayores estaban al mando de los principales hacendados de la región.

31 AHJ. Caja Documento, año 1867, Yavi, 5 de julio de 1867.

32 Archivo Histórico de la Legislatura de Jujuy (en adelante AHLJ). Libro de Actas $\mathrm{N}^{\circ}$ 10, Sesión 21, 9 de marzo de 1863, folios 90 y ss.

33 AHJ. Caja Documento, año 1861, Yavi, 8 de mayo de 1861.

34 AHJ. Caja Documento, año 1861, Santa Catalina, 8 de mayo de 1861. 
35 AHJ. Caja Documento, año 1863, Santa Catalina, 14 de noviembre de 1863.

36 AHLJ. Libro de Actas $N^{\circ}$ 10, Sesión 21, 9 de marzo de 1863, folios 90 y ss., diputado Iturbe.

37 AHLJ. Caja Documentos Nº 27 y 28, años 1871-1872, Comunicación del PE a la Honorable Legislatura, 15/03/1871.

38 Debido a la situación creada en Humahuaca, Tilcara, Yavi y Tumbaya por la retirada del ejército de Varela hacia Bolivia por esa ruta, en 1868 esos departamentos fueron exceptuados del pago de este impuesto.

39 AHLJ. Caja Documentos, $N^{\circ} 27$ y 28, años 1871-1872, Comunicación del PE a la Honorable Legislatura, 15/03/1871. AHLJ. Libros de Actas Nº 12, Sesión 27, 20 de marzo de 1871, fs. 93 y ss. Carecemos de mayores detalles que nos permitan advertir a qué línea ideológica se hace referencia en esta apreciación. No obstante, es de destacar el hecho de la politización que fomentaba la experiencia militar de los sectores populares, tanto de los que podían acceder al pago del impuesto como de aquellos que no tenían otra opción que la conscripción.

40 AHJ. Caja Documento, año 1870, Tumbaya, 9 de junio de 1870 . Similares acciones en AHJ. Caja Documento, año 1866, Humahuaca, 4 de enero de 1866; año 1870, Humahuaca, 29 de mayo de 1870.

41 AHJ. Caja Documento, año 1866, Humahuaca, 4 de enero de 1866.

42 Registro Oficial (1885). Compilación de Leyes y decretos de la provincia de Jujuy. Desde 1853 hasta el de 1884. Tomo III. Jujuy, Tip. Libertad de José Petruzzelli, decretos del 11 de diciembre de 1868 y del 28 de junio de 1869 .

43 Registro Oficial (1885). Compilación de Leyes y decretos de la provincia de Jujuy. Desde 1853 hasta el de 1884. Tomo III. Jujuy, Tip. Libertad de José Petruzzelli, ley del 22 de mayo de 1853 .

44 La contribución territorial que solo pagaban los propietarios desde 1854 se trasladó a los precios de los arriendos que debían afrontar los campesinos indígenas. La contribución mobiliaria desde 1863 reemplazó al diezmo a raíz del cual se cometieron abusos y arbitrariedades contra esos sectores, junto con el impuesto a la extracción de sal y los derechos de aduana a los que ya hemos aludido (Madrazo, 1982).

45 AHJ. Caja documento, año 1867, Yavi, 3 de julio de 1867.

46 AHJ. Caja Documento, año 1867, Yavi, 17 junio de 1867. 
